\title{
Gestão de custos em pequenas propriedades rurais: um estudo aplicado no município de Marechal Cândido Rondon - PR
}

\begin{abstract}
Adriane Carine Maldaner Vorpagel Graduação em Ciências Contábeis pela Universidade Estadual do Oeste do Paraná E-mail: adrianemaldaner@hotmail.com

UNIOESTE

Elza Hofer Doutorado em Administração pela Pontifícia Universidade Católica do Paraná - PUCPR Professora da Universidade Estadual do Oeste do Paraná - UNIOESTE Rua Pernambuco, 1777. Centro. Marechal Candido Rondon/PR. CEP: 85.960-000 E-mail:elza_hofer@uol.com.br

Anderson Giovane Sontag Mestre em Administração pela Universidade Estadual do Oeste do Paraná UNIOESTE Professor da Faculdade Luterana Rui Barbosa - FALURB R. Dom Pedro I, 1151. Centro. Marechal Cândido Rondon/PR. CEP: 85.960-000 E-mail: andersonsontag@hotmail.com
\end{abstract}

\section{RESUMO}

Toda atividade empresarial necessita de planejamento, controle e gestão. Os empresários utilizam-se do conhecimento da administração, contabilidade e economia para gerenciar seus empreendimentos e tomar decisões. No agronegócio e na agricultura familiar, não pode ser diferente. Embora, muitas vezes, o empreendimento não se constitua uma empresa formal, mas a própria pessoa física no exercício de suas atividades, precisam-se de ferramentas gerenciais. Este estudo tem como objetivo verificar se os produtores de Marechal Cândido Rondon - PR utilizam controle de custos no gerenciamento de suas atividades, identificando o perfil, o porte das propriedades e de que maneira essas variáveis podem interferir na gestão e controle das atividades rurais. A pesquisa caracteriza-se por um estudo descritivo, de levantamento, e a coleta de dados desenvolveu-se com a aplicação de questionário. Os resultados da pesquisa foram submetidos a tratamento quantitativo, com análise descritiva. Constatou-se que os produtores possuem muita experiência no desenvolvimento das atividades rurais, mas encontram dificuldades na gestão da sua propriedade. A grande maioria adota um controle de custos informal, com anotações em caderno, sendo que modelos de gestão mais sofisticados são adotados por uma minoria de produtores rurais. $O$ tamanho da propriedade e o faturamento influenciam na gestão, uma vez que, de acordo com o cruzamento de dados, verificou-se que quanto 
Análise da Eficiência da Gestão de Custos do Processo de Produção de Arroz por pequenos e
médios produtores de Limoeiro do Norte - CE

Geanne Benevides Sá Negreiros, Rosângela Venâncio Nunes Rosângela Venâncio Nunes, Charles Washington Costa de Assis, Alexandra Alencar Siebra, Rita de Cássia Fonseca

maior for a propriedade e o faturamento, melhor será o controle de custos das atividades desenvolvidas.

Palavras-chave: Controles Contábeis. Gestão de Custos. Atividades Rurais.

\section{Management of costs in small farms: a study applied in the municipality of Marechal CândidoRondon - PR}

\section{ABSTRACT}

Every business activity requires planning, control and management. Entrepreneurs use the knowledge of management, accounting and economics to manage their enterprises and make decisions. In agribusiness and family farming it can not be different. Although often not made a formal enterprise but in the private individual own in the exercise of his activities, we need management tools. This study aims to verify if the producers of Marechal Cândido Rondon - PR use cost control in the management of their activities. Identifying the profile, the size of the properties and how these variables can interfere in the management and control of rural activities. The research is characterized by a descriptive study, survey and data collection developed with the questionnaire. The results of the research were submitted to quantitative treatment, with descriptive analysis. It was found that the producers have a lot of experience in the development of the rural activities, but they find difficulties in the management of their property. The vast majority adopts control informal costs, notebook notes, and more sophisticated management models are adopted by a minority of farmers. The size of the property and the revenue influence the management, since according to the data crossing it was verified that the greater the property and the revenue, the better will be the cost control of the developed activities.

Keywords: Accounting Controls. Costs management. Farming activities.

\section{INTRODUÇÃO}

O agronegócio brasileiro contribui significativamente para o desenvolvimento econômico de nosso país: "[...] produz um quarto do Produto Interno Bruto (PIB) nacional e aproximadamente um quinto do emprego total" (Buainain, Alves, Silveira, \& Navarro, 2013). O agronegócio é fator importante para o desenvolvimento regional e o fortalecimento da economia. No entanto, diante das dificuldades enfrentadas pelos produtores, fica cada vez mais difícil se manterem na atividade, principalmente devido 

Análise da Eficiência da Gestão de Custos do Processo de Produção de Arroz por pequenos e
médios produtores de Limoeiro do Norte - CE

Geanne Benevides Sá Negreiros, Rosângela Venâncio Nunes Rosângela Venâncio Nunes, Charles Washington Costa de Assis, Alexandra Alencar Siebra, Rita de Cássia Fonseca

às constantes oscilações de preços dos produtos, a lei da oferta e da procura, além dos fatores ambientais, como estiagens, geadas e temporais. Além desses fatores, manterse na atividade rural requer um grande número de investimentos, seja para manter-se na atividade, ampliar a receita ou, até mesmo, para facilitar o manejo das atividades (Araújo, 2013).

Existe uma série de fatores que afetam significativamente o desempenho dos empreendimentos rurais, como a elaboração de projetos agrícolas para solicitação de crédito, a tomada de decisão sobre o que produzir, a tecnologia a ser adquirida, o processo de compra de insumos e venda dos produtos, entre outros, exigindo capacitações gerenciais, ausentes na maioria dos produtores rurais, inclusive os familiares, provocando impactos negativos no desenvolvimento desse segmento e, consequentemente, na sua integração aos mercados mais dinâmicos (Lourenzani, 2006).

Toda atividade empresarial necessita de planejamento, controle e gestão. Os empresários utilizam-se do conhecimento da administração, contabilidade e economia para gerenciar seus empreendimentos e tomar decisões. No agronegócio e na agricultura familiar, não pode ser diferente. Embora, muitas vezes, o empreendimento não se constitua uma empresa formal, mas a própria pessoa física no exercício de suas atividades, são necessárias ferramentas gerenciais.

O agricultor está se transformando em empresário rural, em um administrador profissional que, além de se preocupar com a produção, busca a produtividade e a lucratividade, produzindo mais com menos recursos e necessitando, para isso, de informações para avaliar, controlar e decidir. Ainda, as propriedades no futuro tendem a ser verticalizadas e integradas à agroindústria, havendo a transição da fazenda familiar para a empresa familiar (Marion \& Segatti, 2005). O suporte para o gerenciamento do negócio rural pode ser obtido por meio da contabilidade. No entanto, conforme Hofer, Pacheco, Souza e Protil (2011), a grande maioria dos produtores rurais administra suas atividades na informalidade, utilizando-se apenas de simples anotações. 
Análise da Eficiência da Gestão de Custos do Processo de Produção de Arroz por pequenos e
médios produtores de Limoeiro do Norte - CE

Geanne Benevides Sá Negreiros, Rosângela Venâncio Nunes Rosângela Venâncio Nunes, Charles Washington Costa de Assis, Alexandra Alencar Siebra, Rita de Cássia Fonseca

Considerando a relevância das atividades desenvolvidas no meio rural para o desenvolvimento econômico e as vantagens oferecidas pela contabilidade aos seus usuários, busca-se responder o seguinte questionamento: os produtores rurais do município de Marechal Cândido Rondon - PR utilizam algum controle de custos na gestão de suas atividades? O objetivo da pesquisa é verificar em que medida os produtores rurais utilizam as informações da contabilidade de custos no gerenciamento de suas atividades. Busca-se ainda identificar o perfil dos entrevistados, qual o porte das propriedades pesquisadas e de que maneira essas variáveis podem interferir na gestão e controle das atividades rurais.

O presente trabalho justifica-se pela importância do agronegócio para o sustento da população, de sua relevância para o bom andamento da economia, pela geração de emprego e renda, obtendo maior acompanhamento das atividades rurais a fim de auxiliar o produtor rural na gestão de seus negócios, de forma que este possa obter bons resultados financeiros que permitam a continuidade de suas atividades.

A pesquisa está organizada em mais quatro seções além desta Introdução. $\mathrm{Na}$ sequência, é apresentada a fundamentação teórica, que aborda a contabilidade rural e de custos. Na terceira seção, descrevem-se os procedimentos metodológicos; na quarta, a análise dos dados e resultados; por fim, as considerações finais e as referências que sustentaram a justificativa e a argumentação do trabalho.

\section{FUNDAMENTAÇÃO TEÓRICA}

A Contabilidade Rural, apesar de sua extrema importância, ainda é pouco utilizada no Brasil. Isto se deve, principalmente, pelo desconhecimento das vantagens proporcionadas pelo seu uso no desenvolvimento das atividades rurais, além de que muitos empresários desse ramo primam pelos controles baseados na experiência adquirida e passam a abrir mão das informações reais (Crepaldi, 2009).

A contabilidade é peça fundamental na gestão dos empreendimentos rurais, uma vez que o empreendedor rural, agricultor ou pecuarista, deve possuir, em mãos, 

Análise da Eficiência da Gestão de Custos do Processo de Produção de Arroz por pequenos e
médios produtores de Limoeiro do Norte - CE

Geanne Benevides Sá Negreiros, Rosângela Venâncio Nunes Rosângela Venâncio Nunes, Charles Washington Costa de Assis, Alexandra Alencar Siebra, Rita de Cássia Fonseca

ferramentas que o auxiliam na tomada de decisão. Com o uso da contabilidade, o empresário rural poderá dispor de informações financeiras de sua atividade, se o desempenho de sua produção é rentável e souber qual a melhor forma para otimizar seus resultados. De modo geral, terá em mãos dados que lhe permitam estabelecer relações entre diferentes departamentos, de forma que possa tomar decisões acertadas quanto a novos investimentos e quanto ao futuro da organização (Barbosa, 2008).

$\mathrm{Na}$ gestão realizada pelos empresários rurais, estes, na maioria das vezes, sequer fazem anotações sobre suas operações financeiras, guardando os registros em sua memória, que, com o tempo, são esquecidos. De modo geral, não há separação das despesas particulares e das atividades da empresa; logo, não se faz apuração de lucro, o que impossibilita a verificação da rentabilidade do negócio e impede a minimização de custos de produção (Crepaldi, 2009).

Existem alguns obstáculos para o uso da contabilidade no meio rural, os quais se referem principalmente ao elevado custo de manutenção dos serviços contábeis, à dificuldade de separar os custos de produção dos gastos do próprio empresário, desrespeitando o princípio da entidade, além da ausência de recibos, notas fiscais, cópias de cheques ou extratos de contas bancárias (Crepaldi, 2009).

A administração ou uso de técnicas de gerenciamento, controle ou organização da propriedade rural ainda são pouco aceitas pelos produtores, pois muitos deles pensam que dedicar-se a qualquer atividade que não seja a atividade pecuária e agrícola é perda de tempo. Os produtores que utilizam algum tipo de controle, que geralmente ocorre por meio de anotações em papel ou apenas guardam as informações na própria memória, dispensam qualquer tipo de anotação. Poucos são os que utilizam métodos mais sofisticados, como planilhas eletrônicas ou sistemas computadorizados. Casos do tipo podem ser explicados pela idade avançada e baixa escolaridade dos gestores que, por vezes, não sabem utilizar um computador ou sequer possuem este equipamento em sua propriedade (Souza Filho \& Batalha, 2005).

O empresário rural carece do uso de métodos de planejamento de suas atividades, como: observar seus pontos fortes e fracos, comparando o desempenho de 

Análise da Eficiência da Gestão de Custos do Processo de Produção de Arroz por pequenos e
médios produtores de Limoeiro do Norte - CE

Geanne Benevides Sá Negreiros, Rosângela Venâncio Nunes Rosângela Venâncio Nunes, Charles Washington Costa de Assis, Alexandra Alencar Siebra, Rita de Cássia Fonseca

cada uma delas com períodos anteriores; fazer o controle de suas receitas e despesas, além de fazer estimativas de custos e da rentabilidade que poderia ser obtida em possíveis investimentos (Barbosa, 2008).

Para Crepaldi (2009), o empresário rural necessita do auxílio de um profissional para a contabilização de suas atividades. Em posse dos relatórios, o administrador terá em mãos ferramentas que indicaram quais as melhores tendências do mercado, podendo explorar, de maneira adequada, seu ciclo produtivo, além de realizar um controle efetivo dos insumos utilizados na produção, diminuindo desperdícios e maximizando o lucro.

A adoção de ferramentas de gestão nas propriedades rurais não é tão simples assim, já que, para se solucionar essa questão, precisa-se mudar a cultura dos produtores e dos consultores técnicos que lhes dão assistência, pois o desleixo ao uso das ferramentas de gestão pode comprometer a sustentabilidade e competitividade desses empreendimentos rurais (Souza Filho \& Batalha, 2005). Para Debertolis, Alexius e Dossa (2005), "a gestão rural pode ser [...] o uso de forma eficiente e eficaz dos recursos naturais, humanos, físicos e financeiros, [...], de todas as atividades desenvolvidas, mediante planejamento, a organização, a direção, o controle, [...]".

Para Callado e Moraes Filho (2011), o gerenciamento e controle das empresas rurais podem ser classificados quanto ao porte das propriedades. As pequenas empresas, em sua maioria, controlam suas contas a pagar e a receber, além dos serviços e outros registros, por meio de anotações em uma simples caderneta. Já as médias empresas utilizam registros não somente das contas pendentes como, em todas as operações e negócios realizados, dispõe do livro diário, registros dos empregados e das contas correntes. Por fim, as grandes empresas utilizam a contabilidade financeira completa e de rigorosos registros para o controle das transações.

O gestor rural, conhecedor de seu negócio, toma decisões com base nos dados reais das operações desenvolvidas na propriedade, busca conhecer as atividades para poder trabalhar com riscos calculados e tomar decisões acertadas (Debertolis et al., 2005). 
Análise da Eficiência da Gestão de Custos do Processo de Produção de Arroz por pequenos e médios produtores de Limoeiro do Norte - CE

Geanne Benevides Sá Negreiros, Rosângela Venâncio Nunes Rosângela Venâncio Nunes, Charles Washington Costa de Assis, Alexandra Alencar Siebra, Rita de Cássia Fonseca

De acordo com Callado e Moraes Filho (2011), o administrador rural deve ser capaz de tomar decisões acertadas diante das diversas alternativas que o mercado lhe oferece, optando pela possibilidade que traga benefícios à sua empresa, sem infringir a legislação. Decisões importantes na gestão da entidade estão relacionadas ao controle de custos, o que significa que o gestor deve estar atento aos custos relevantes, buscando sempre reduzir seus custos, maximizar sua produção, sem que o produto final perca sua qualidade.

Segundo Crepaldi (2009), a boa gestão é realizada quando se tem informações confiáveis e concretas para serem analisadas, o que permite a tomada de decisões acertadas; no entanto, esta é justamente a maior dificuldade dos produtores rurais que, pela falta de instrução, não sabem lidar com certas informações. Para Debertolis et al. (2005), os principais aspectos a serem observados no gerenciamento de uma propriedade rural são: controle de custos, de receitas e a margem de lucro de cada uma das atividades.

Desse modo, diante das diversas especificidades das atividades agrícolas e pecuárias, o gestor rural deve capacitar-se, de modo que seja capaz de fazer análises quanto à viabilidade da realização de investimentos em determinada atividade. Para isso, o administrador rural disporá de técnicas de análise financeira, de investimento e de risco (Simprini \& Lopes, 2012).

\subsection{Custos na Agropecuária}

Toda administração de qualidade requer um bom planejamento. A gestão de custos ideal inicia-se com uma previsão de custos, estimando-se custos e receitas, buscando-se aproximá-los da realidade para se ter um prognóstico sobre gastos e lucros. O controle de gastos da propriedade deve ser observado e tabulado diariamente e, ao final da semana e do mês, elaborado resultado parcial para poder constantemente acompanhar o comportamento dos custos e gastos das atividades e prever antecipadamente a ocorrência de possíveis prejuízos (Araújo, 2013). 
Análise da Eficiência da Gestão de Custos do Processo de Produção de Arroz por pequenos e médios produtores de Limoeiro do Norte - CE

Geanne Benevides Sá Negreiros, Rosângela Venâncio Nunes Rosângela Venâncio Nunes, Charles Washington Costa de Assis, Alexandra Alencar Siebra, Rita de Cássia Fonseca

Ainda a maioria dos pequenos produtores rurais trabalha no sistema de integração ou comercializa sua produção por intermédio de cooperativas; logo, não demonstram interesse em saber qual o verdadeiro custo de sua produção ou criação, considerando que possuem a garantia de venda de seus produtos (Batalha, Buainain, \& Souza Filho, 2005). No entanto, se o produtor soubesse o custo real de seus produtos, poderia aumentar seu poder de barganha (Souza Filho \& Batalha, 2005).

É imprescindível que os empresários rurais realizem a gestão de custos, facilitando o acompanhamento das alterações patrimoniais ocorridas. Assim, a aplicação de uma contabilidade, mesmo que simplificada, permite o acompanhamento e registro dos valores de sua propriedade e de todas as operações realizadas no exercício, possibilitando a análise das causas que concorrem para os lucros ou prejuízos (Callado \& Callado, 2011).

Nessa perspectiva, Simprini e Lopes (2012) complementam que um empreendimento rural se torna competitivo no mercado a partir do momento em que estiver à frente dos concorrentes. Para atingir esse propósito, deve produzir produtos com mais qualidade do que os do concorrente, a um custo melhor, além de transmitir confiabilidade aos clientes e possuir uma boa localização geográfica de seu empreendimento.

Ainda, Godinho, Soares, Bertipaglia, \& Dian (2013) identificaram e correlacionaram aspectos relevantes da gestão empresarial em sistemas de produção de leite de um município do Sudoeste de Minas Gerais. Em pesquisa realizada junto aos produtores rurais e profissionais da assistência técnica com vínculo com a produção leiteira, avaliaram-se as percepções quanto ao entendimento de gestão, a prática do planejamento, organização, direção e controle. Constatou-se que o baixo uso de técnicas de gestão nos sistemas de produção leiteira possui uma relação com o baixo envolvimento dos profissionais da assistência técnica com as questões administrativas dessas empresas que exploram esses sistemas.

Na mesma linha, Breitenbach, Brandão e Vitali (2016) buscaram identificar o perfil gerencial de agricultores familiares, produtores de soja do Rio Grande do Sul, 
Análise da Eficiência da Gestão de Custos do Processo de Produção de Arroz por pequenos e médios produtores de Limoeiro do Norte - CE

Geanne Benevides Sá Negreiros, Rosângela Venâncio Nunes Rosângela Venâncio Nunes, Charles Washington Costa de Assis, Alexandra Alencar Siebra, Rita de Cássia Fonseca

definindo o nível de administração e o conhecimento em relação aos custos relacionados à atividade que desenvolvem. Os resultados apontaram que $99,5 \%$ dos agricultores têm pouca noção dos lucros das atividades, $87,3 \%$ têm conhecimento aproximado de custos das atividades e apenas $30 \%$ consideram-se "organizados" e "muito organizados" nos controles da propriedade.

\section{PROCEDIMENTOS METODOLÓGICOS}

A presente pesquisa, quanto aos objetivos, enquadra-se como descritiva, sendo utilizada principalmente quando se objetiva realizar aplicação de questionários ou quando se deseja realizar uma observação sistemática (Andrade, 2003). Quanto aos procedimentos, trata-se de uma pesquisa survey ou levantamento, caracterizado pela interrogação direta às pessoas, extraindo-lhes as informações que se deseja conhecer (Raupp \& Beuren, 2012). Em relação à abordagem do problema, trata-se de uma pesquisa quantitativa, com uso de métodos estatísticos na análise dos dados.

A população constitui os produtores rurais do município de Marechal Cândido Rondon - PR, que, de acordo com o Instituto Brasileiro de Geografia e Estatística [IBGE] (2006), somam 2.423 empreendimentos rurais. A amostra são 130 produtores rurais entrevistados, ou seja, $5,36 \%$ da população. A amostra foi selecionada de forma não probabilística, por acessibilidade e erro amostral de 8,5\%.

Para fins desta pesquisa, a coleta dos dados foi realizada por meio de questionário estruturado, seguindo um roteiro de perguntas pré-determinadas para atender os objetivos previamente propostos, compreendendo 35 questões fechadas. Além de seguir um roteiro com questionamentos previamente estabelecidos, a interrogação direta possibilitou o contato aberto com os entrevistados, o que permitiu que estes expusessem o seu ponto de vista sobre os questionamentos realizados e sobre a situação da gestão da propriedade.

O questionário foi organizado em três partes: a primeira possui 10 questões que identificam o perfil dos produtores rurais, sua idade, escolaridade, se possui filhos e 
Análise da Eficiência da Gestão de Custos do Processo de Produção de Arroz por pequenos e
médios produtores de Limoeiro do Norte - CE

Geanne Benevides Sá Negreiros, Rosângela Venâncio Nunes Rosângela Venâncio Nunes, Charles Washington Costa de Assis, Alexandra Alencar Siebra, Rita de Cássia Fonseca

tempo de atividade rural. No segundo tópico, verificam-se as características da propriedade, elencando 17 questões a respeito de faturamento, o tamanho da propriedade, forma de aquisição do patrimônio e quais as culturas desenvolvidas. A terceira parte refere-se à gestão da propriedade e ao controle de custos das atividades rurais. Este último tópico procurou, por meio de 8 questões, constatar se os produtores utilizam algum método de controle, como é realizado, os benefícios percebidos e se tem interesse em adotar a contabilidade em suas atividades.

Para a aplicação da pesquisa, realizou-se a abordagem dos produtores que frequentavam a unidade sede de uma cooperativa agropecuária do município, no dia escolhido, para fazer as entrevistas. Além disso, realizaram-se visitas às propriedades rurais, tendo sido entrevistados produtores de diversas regiões do município. A coleta dos dados foi realizada entre os dias 03/06/2014 e 19/07/2014, em dias aleatórios, tanto no período matutino, vespertino, quanto no noturno, dependendo da disponibilidade do entrevistador em fazer as visitas.

Após coletados os dados, as respostas foram tabuladas em planilhas de Excel, compiladas em tabelas. Alguns dados foram submetidos ao cruzamento de dados por meio do Software SPSS, Versão 22, permitindo, por meio de tabela cruzada, verificar como uma variável se comporta em relação à outra. A análise estabeleceu a relação entre os controles de custos com a faixa etária dos pesquisados, o tamanho da propriedade, o faturamento, o financiamento e as informações de mercado.

\section{ANÁLISE DOS DADOS E DISCUSSÃO DOS RESULTADOS}

Nesta seção, são abordados o perfil dos produtores rurais, as características das propriedades rurais e as ferramentas de controle e gestão utilizadas na atividade rural.

\subsection{Perfil dos Produtores Rurais}

Nessa seção, é apresentado o perfil dos produtores rurais entrevistados. Em relação ao gênero, $80 \%$ são do sexo masculino e $20 \%$ feminino. Essa disparidade de 
Análise da Eficiência da Gestão de Custos do Processo de Produção de Arroz por pequenos e médios produtores de Limoeiro do Norte - CE

Geanne Benevides Sá Negreiros, Rosângela Venâncio Nunes Rosângela Venâncio Nunes, Charles Washington Costa de Assis, Alexandra Alencar Siebra, Rita de Cássia Fonseca

gênero leva a crer que o homem está mais envolvido na atividade rural que a mulher, seja no serviço braçal, seja na gestão dos negócios. Percebeu-se também, durante a aplicação das entrevistas, que as mulheres acompanham seus maridos na gestão, mas quem ainda toma a frente nas contas da família é o homem. Esses dados refletem a realidade nacional em que $87 \%$ dos estabelecimentos são dirigidos por homens (IBGE, 2006).

No que se refere à idade dos respondentes, constatou-se que a população jovem na qual estão incluídas pessoas com menos de 20 anos até os 30 anos, representam juntos, apenas $8 \%$ da população de produtores rurais, a faixa que compreende agricultores de 31 a 40 anos é representada por $7 \%$. Dos produtores entrevistados, $31 \%$ disseram enquadrar-se na faixa etária dos 41 aos 50 anos, 33\% dos 51 aos 60 , enquanto que os produtores acima de 61 anos representaram 21\%. Percebe-se que uma das características dessa atividade é possuir profissionais com maior maturidade, pois, como observado, são poucos os profissionais jovens neste setor, e a maioria dos produtores rurais possui de 41 a 60 anos de idade, ou seja, $86 \%$.

Em relação ao estado civil, observam-se $88 \%$ dos produtores rurais. Casados (6\%), solteiros (2\%) e viúvos (4\%) não fazem parte desses estados civis que, em sua maioria, são os casais em união estável, que decidem viver juntos, mas não são casados perante a lei.

Quanto ao grau de instrução durante a entrevista, nenhum dos entrevistados se manifestou como sendo analfabeto; por outro lado, verificou-se que $29 \%$ dos pesquisados possuem apenas o Ensino Fundamental incompleto; 35\% completaram o Ensino Fundamental; 4\% disseram não ter concluído o Ensino Médio; e 22\% dos 130 entrevistados disseram possuir o Ensino Médio completo. Fato importante é que $10 \%$ dos produtores estão cursando ou concluíram o Ensino Superior, demonstrando que, mesmo ainda sendo poucos, existem produtores que estão interessados no crescimento profissional do homem do campo.

No que se refere ao tempo em que atua na atividade rural, quase a totalidade dos produtores atua mais de 20 anos nessa área, de modo que $87 \%$ afirmaram atuar a 
Análise da Eficiência da Gestão de Custos do Processo de Produção de Arroz por pequenos e
médios produtores de Limoeiro do Norte - CE

Geanne Benevides Sá Negreiros, Rosângela Venâncio Nunes Rosângela Venâncio Nunes, Charles Washington Costa de Assis, Alexandra Alencar Siebra, Rita de Cássia Fonseca

vida toda nesta atividade, e os demais 13\% estão distribuídos entre os profissionais que atuam de 5 a 20 anos no setor.

\subsection{Características da Propriedade Rural}

A caracterização da propriedade é de fundamental importância para a compreensão da gestão de custos e do controle das atividades. Assim, 94\% dos produtores rurais são proprietários da área em que desenvolvem as suas atividades; alguns deles também arrendam terras de terceiros. Apenas $6 \%$ não possuem área própria e operam por meio da exploração de propriedades de terceiros. Comparativamente, os dados do censo agropecuário indicavam que o município apresentava uma concentração de $86 \%$ de estabelecimentos rurais próprios em 2006 (IBGE, 2006; Instituto Paranaense de Desenvolvimento Econômico e Social, IPARDES, 2017).

Dos 130 produtores entrevistados, 94\% possuem área própria, sendo que $31 \%$ obtiveram sua área de terra por meio de herança, 1\% adquiriu parte da propriedade com herança e parte com financiamento; $47 \%$ obtiveram sua área por meio de herança e com a renda da própria atividade. Ainda 15\% não tiveram nenhum incentivo, ou seja, adquiriram suas terras utilizando-se de recursos próprios. Os demais 6\% são representados pelos produtores que não possuem área própria, já que arrendam terras de terceiros.

Além da terra, o desenvolvimento das atividades rurais requer inúmeros investimentos, tais como: construção de infraestrutura, maquinários, equipamentos e insumos. Para conseguir manter a atividade, muitos produtores necessitam utilizar-se de incentivos financeiros, outros, porém, por possuírem um bom capital de giro, realizam investimentos por meio de recursos próprios, geralmente oriundos da renda da própria atividade. Neste sentido, Buainain et al. (2013) comentam que a produção e as rendas agropecuárias passam a depender, crescentemente, de investimentos e capital de giro para introduzir no sistema produtivo os insumos que viabilizam as inovações para manter-se rentável em ambientes de crescente tensionamento concorrencial. 

Análise da Eficiência da Gestão de Custos do Processo de Produção de Arroz por pequenos e
médios produtores de Limoeiro do Norte - CE

Geanne Benevides Sá Negreiros, Rosângela Venâncio Nunes Rosângela Venâncio Nunes, Charles Washington Costa de Assis, Alexandra Alencar Siebra, Rita de Cássia Fonseca

Em relação à forma de aumento patrimonial nos últimos 10 anos: $20 \%$ justificam que o aumento patrimonial se deve pela renda das próprias atividades; $42 \%$ pela obtenção de financiamentos e pela renda própria; 7\% somente utilizaram financiamento; $20 \%$ pela diversificação de culturas agrícolas e pecuárias; $10 \%$ por meio de herança; e 1\% utilizou outros meios para aumentar o patrimônio. Os produtores podem utilizar-se de diferentes formas de aumento de patrimônio.

A renda da propriedade, aliada ao financiamento, é o elemento que mais contribui para aumentar os investimentos e, como consequência, o patrimônio. A renda própria e os financiamentos são recursos que estão intimamente ligados, tanto que, para a obtenção de financiamento, o usuário deverá possuir renda para que consiga honrar os seus empréstimos.

De 130 produtores entrevistados, 52 exploram propriedades de terceiros, seja na forma de arrendamento, parceria rural ou comodato. Isso, em termos percentuais, significa que, do total de entrevistados, $40 \%$ dos produtores obtêm renda por meio da exploração de propriedades de terceiros, enquanto que $60 \%$ cultivam apenas área própria.

Considerando apenas os produtores que utilizam terras de terceiros, dos $73 \%$ dos produtores que exploram terras de terceiros, por meio do regime de arrendamento (contrato agrário por determinado período de tempo), 25\% deles adotam a parceria rural (associação com terceiros), e apenas 2\% utilizam o comodato (empréstimo gratuito da área para cultivo).

Durante a realização das entrevistas, percebeu-se que muitos agricultores com idade avançada, que estão sozinhos na atividade, pois seus filhos deixaram o campo em busca de estudos ou realização profissional, têm no arrendamento a única alternativa para a continuidade da atividade. Estes pequenos produtores geralmente arrendam suas terras para produtores maiores, que possuem maquinário e infraestrutura para o cultivo da mesma.

Em relação ao tamanho da propriedade, a amostra de 130 produtores rurais do município de Marechal Candido Rondon - PR é constituída por pequenos produtores 


\section{Análise da Eficiência da Gestão de Custos do Processo de Produção de Arroz por pequenos e médios produtores de Limoeiro do Norte - CE}

Geanne Benevides Sá Negreiros, Rosângela Venâncio Nunes Rosângela Venâncio Nunes, Charles Washington Costa de Assis, Alexandra Alencar Siebra, Rita de Cássia Fonseca

rurais. A pesquisa demonstra que $45 \%$ das propriedades do município são classificadas como minifúndio, ou seja, possuem área inferior a um módulo fiscal, o que equivale a 18 hectares; 44\% das propriedades são classificadas como de pequena propriedade rural, possuindo de 1 a 4 módulos fiscais (18 a 72 hectares); 11\% incluem-se na média propriedade por possuírem de 4 a 15 módulos (72 a 270 hectares); e, por fim, 1 produtor entrevistado se classifica como grande propriedade rural, por possuir mais de 15 módulos fiscais, ou seja, uma área superior a 270 hectares.

Quanto às culturas desenvolvidas nas propriedades, verificou-se que a maioria dos entrevistados possui mais de uma atividade como fonte de renda da propriedade. Isso se explica principalmente pelas oscilações de preços, pelas intempéries e porque, muitas vezes, uma atividade complementa a outra, tornando-se viável o desenvolvimento em conjunto. Ressalta-se que essa questão permitia a opção de várias alternativas. De acordo com os agricultores entrevistados: $91 \%$ cultivam milho; $75 \%$ soja; $62 \%$ lidavam com atividade leiteira; $19 \%$ com suinocultura; 12\% com piscicultura; $13 \%$ com gado de corte; $9 \%$ com trigo, $8 \%$ com aviários e $31 \%$ praticam outras atividades.

Em relação a "outras atividades", destaca-se a horticultura, fruticultura, pastagem, mandioca, plantio de chia, feno, embutidos de carne animal, plantação de eucalipto, aveia, sorgo e cultivo de orquídeas. Dessas atividades citadas, a que teve maior relevância, por ter sido mencionada por vários agricultores, é o cultivo da mandioca, seguido da pastagem, porém esta última serve como complemento à produção leiteira, não sendo uma fonte de geração de receita isolada.

Quanto às atividades rurais que representam maiores receitas nas propriedades, mencionam-se: $29 \%$ de milho, $27 \%$ de soja, $22 \%$ de pecuária de leite e, na sequência, produtos que não tiveram uma representatividade tão significativa: a suinocultura - 7\%, avicultura - 3\%, piscicultura - $2 \%$, pecuária de corte - $2 \%$ e, por último, o cultivo de trigo - 1\%. O censo agropecuário de 2006 apresentava como principal renda dos estabelecimentos rurais as lavouras temporárias, com 44\%, e a pecuária, com 53\% no município (IBGE, 2006; IPARDES, 2017). 
Análise da Eficiência da Gestão de Custos do Processo de Produção de Arroz por pequenos e médios produtores de Limoeiro do Norte - CE

Geanne Benevides Sá Negreiros, Rosângela Venâncio Nunes Rosângela Venâncio Nunes, Charles Washington Costa de Assis, Alexandra Alencar Siebra, Rita de Cássia Fonseca

Considerando que uma característica das propriedades é a diversificação de culturas, $50 \%$ dos produtores optam pela diversificação de culturas devido à maior rentabilidade (resultados financeiros obtidos); 19\% consideram que a diversificação gera menor demanda por mão de obra.

Ainda $14 \%$ optam pela diversificação devido à linha de financiamento oferecida; $36 \%$ preocupam-se com a preservação do solo; $38 \%$ possuem afinidade e experiência pessoal, ou seja, trata-se de atividades das quais os produtores gostam e nas quais possuem experiência. Além disso, 35\% desenvolvem as atividades para aproveitar a estrutura já existente e $8 \%$ restantes possuem outros motivos, como o desenvolvimento conjunto de várias culturas por se complementarem. O desenvolvimento de diferentes atividades proporciona maior segurança quanto à renda do produtor, pois, quando uma atividade está em crise, a outra gera renda.

Analisando a relação entre o tamanho da propriedade e o faturamento anual, percebe-se que, apesar de o município possuir um número significativo de minifúndios e pequenas propriedades, a receita obtida na exploração das atividades é significativa. Isso pode ser explicado pelos períodos de geração de receita de cada atividade. Uma propriedade que pratica a atividade leiteira tem geração de receita durante os doze meses do ano, enquanto que um produtor de milho obtém receita apenas duas vezes ao ano, e da soja, apenas uma vez.

Desse modo, os dados obtidos demonstram que $26 \%$ dos produtores possuem geração de receita bruta anual de $25.000,00$ a 50.000,00 reais, $23 \%$ arrecadam de $50.000,00$ a $100.000,00$ reais anualmente, $36 \%$ faturam de $100.000,00$ a $250.000,00$ reais. Os valores mais significativos, como de $250.000,00$ a $500.000,00$ reais, provêm de $10 \%$ dos produtores; de 500.000,00 a 1.000.000,00, 2\%; e acima de 1.000.000,00, somente $3 \%$.

Os proprietários rurais necessitam de recursos financeiros para o desenvolvimento de suas atividades, sendo utilizados no custeio de atividades produtivas, em projetos de investimento, em atividades de comercialização da produção e no suprimento das necessidades familiares. Os gastos incorridos durante o ciclo de 

Análise da Eficiência da Gestão de Custos do Processo de Produção de Arroz por pequenos e
médios produtores de Limoeiro do Norte - CE

Geanne Benevides Sá Negreiros, Rosângela Venâncio Nunes Rosângela Venâncio Nunes, Charles Washington Costa de Assis, Alexandra Alencar Siebra, Rita de Cássia Fonseca

produção e as receitas provenientes das vendas dos produtos, por vezes, apresentam uma defasagem que precisa ser equacionada com recursos próprios ou captados externamente (Mundo Neto, \&Souza Filho, 2005). Nesse sentido, dos 130 produtores entrevistados, $93 \%$ já efetuaram algum tipo de financiamento, contra $7 \%$ que nunca realizaram este tipo de operação.

Para $64 \%$ dos produtores, a contratação de financiamento foi necessária para melhorar a atividade na substituição de maquinários e equipamentos; 61\% consideraram que os recursos apresentavam taxas de juros atraentes; $48 \%$ como uma alternativa para ampliar a receita da família e diversificação. Ainda, $45 \%$ buscaram recursos por necessidade e como uma alternativa para o desenvolvimento das atividades; 29\% realizaram investimentos em nova atividade, com os recursos financiados; e 59\% buscaram financiamentos para bancar o custeio dos insumos.

Os financiamentos contratados foram investidos em diversos setores: máquinas e equipamentos em $66 \%$ dos casos; custeio dos insumos em $50 \%$; pecuária de leite em $38 \%$; suinocultura em $16 \%$; avicultura em $8 \%$; e piscicultura em $5 \%$, sendo a área que menos recebeu investimentos. Outras áreas que receberam investimentos foram: fruticultura, horticultura, pecuária de corte, instalações e estufas.

De acordo com a pesquisa, $89 \%$ dos respondentes que realizaram financiamentos para investimentos obtiveram lucro devido aos investimentos que realizaram; apenas 4\% não obtiveram lucros. Vale ressaltar que 9 produtores alegaram nunca ter realizado financiamentos. Isso não significa que não tenham investido em suas atividades, apenas não utilizaram recursos de terceiros para realizá-los. Destacase que as linhas de financiamento, como Pronaf e microcrédito rural utilizadas, não foram questionadas na pesquisa.

Ainda $97 \%$ dos pesquisados utilizam mão de obra familiar; destes, $85 \%$ de forma exclusiva, 3\% não utilizam, ou seja, 4 pessoas desenvolvem a agricultura exclusivamente patronal. Em relação ao número de funcionários, 10\% possuem de 1 a 2; $3 \%$ de 3 a 5 ; e $2 \%$ acima de 10 funcionários. 
Análise da Eficiência da Gestão de Custos do Processo de Produção de Arroz por pequenos e médios produtores de Limoeiro do Norte - CE

Geanne Benevides Sá Negreiros, Rosângela Venâncio Nunes Rosângela Venâncio Nunes, Charles Washington Costa de Assis, Alexandra Alencar Siebra, Rita de Cássia Fonseca

Embora não possuam funcionários, $93 \%$ dos produtores rurais utilizam-se de serviços de terceiros. Isso ocorre geralmente em períodos de plantio e colheita, pois nem todos os produtores rurais possuem equipamentos e maquinários para tal fim, optando por terceirizar este serviço. $O$ uso de serviços de terceiros também ocorre quando há um acúmulo ou um grande volume de trabalhos a serem desenvolvidos e quando há a necessidade de assessoramento da produção por um profissional especializado. Dos serviços mencionados, os serviços gerais representam apenas $26 \%$, enquanto que o plantio, a colheita e a preparação do solo correspondem a $71 \%$, e o que possui maior demanda dos produtores é a assistência técnica agronômica e veterinária, com $87 \%$ dos respondentes.

Os produtores ainda foram questionados quanto à participação em entidades associativas: $85 \%$ participam em cooperativas agropecuárias; $72 \%$ em cooperativas de crédito; $64 \%$ em cooperativas de eletrificação rural; $52 \%$ em associação de moradores; $45 \%$ em sindicato de trabalhadores rurais; $17 \%$ em associação de produtores de leite; $8 \%$ em associação de suinocultores; e 1\% em associação de piscicultores.

\subsection{Ferramentas de Controle e Gestão Utilizadas na Atividade Rural}

Nessa seção, são apresentadas as principais ferramentas de controle e gestão utilizados pelos pesquisados na atividade rural. Questionados sobre acesso à internet, $66 \%$ dizem ter acesso na propriedade. A rede mundial de computadores, apesar de não exercer influência direta sobre a gestão das atividades rurais, desempenha um papel fundamental, que é a informação e a comunicação. Por meio da internet, o produtor pode inteirar-se das tendências de seu negócio: como anda a agricultura em termos mundiais e nacionais, entre outros benefícios.

Dos 86 produtores que disseram possuir acesso à internet em suas propriedades, nem todos utilizam este recurso. Alguns afirmaram que o uso da internet é realizado exclusivamente pelos filhos, principalmente para fins acadêmicos. Por outro lado, percebeu-se que alguns produtores realmente demonstram interesse em 
Análise da Eficiência da Gestão de Custos do Processo de Produção de Arroz por pequenos e médios produtores de Limoeiro do Norte - CE

Geanne Benevides Sá Negreiros, Rosângela Venâncio Nunes Rosângela Venâncio Nunes, Charles Washington Costa de Assis, Alexandra Alencar Siebra, Rita de Cássia Fonseca

atualizar-se, seja para conectar-se virtualmente, seja para manusear o computador para a realização de controles de gestão.

Em relação ao acesso às informações, $58 \%$ dos produtores baseiam-se em informações, como o preço das commodities no mercado agrícola e cotação do dólar para a tomada de decisão quanto à comercialização dos seus produtos. Os $42 \%$ dos produtores que não se utilizam de informações de mercado, por vezes, vendem seus produtos por necessidade para honrar seus compromissos financeiros de custeio, não possuindo capital de giro para aguardar o melhor momento de venda.

Questionados se os respondentes realizam controle de custos, despesas e receitas na propriedade, $89 \%$ dos produtores da amostra utilizam algum método de controle, contra $11 \%$ dos entrevistados que não o fazem. Ideal seria que este procedimento fosse utilizado por todos os profissionais, seja da área rural ou não, por mais simples e rudimentar que fosse.

Os controles contábeis e de custos revelam o andamento da atividade: se está dando lucro, se o negócio é viável, quando ocorrem as entradas e saídas de dinheiro. Enfim, são as ferramentas e/ou melhor maneira para controlar o patrimônio.

Quanto à forma como é realizado o controle na propriedade, $21 \%$ afirmam fazer o controle informal, sem anotações, apenas mentalmente, o que leva a crer que, por vezes, alguns controles passam despercebidos. Sessenta e três porcento (63\%) dos produtores fazem o controle manual de suas atividades por meio de anotações em um caderno. Além desses controles, $13 \%$ dos produtores administram suas atividades com apoio de planilhas no Excel, e 3\% possuem sistemas informatizados próprios ou realizam contabilidade em escritório terceirizado. Alguns produtores alegaram utilizar mais de um tipo de controle, como o informal, associado ao controle manual ou controle manual,juntamente com planilhas informatizadas em Excel.

No entendimento dos produtores rurais entrevistados, os objetivos da gestão da propriedade são: controle de custos - $63 \%$; planejamento futuro das atividades - $55 \%$; apuração do lucro - 48\%; controle do fluxo de caixa - 47\%; e para atender exigências fiscais - $19 \%$. Em se tratando do uso da contabilidade na gestão rural, a pesquisa 
Análise da Eficiência da Gestão de Custos do Processo de Produção de Arroz por pequenos e médios produtores de Limoeiro do Norte - CE

Geanne Benevides Sá Negreiros, Rosângela Venâncio Nunes Rosângela Venâncio Nunes, Charles Washington Costa de Assis, Alexandra Alencar Siebra, Rita de Cássia Fonseca

buscou saber se os produtores a utilizam para planejar e projetar investimentos futuros. Assim, $77 \%$ dos respondentes utilizam a contabilidade de custos para planejamento de investimentos futuros, enquanto que $23 \%$ não a utilizam.

Os produtores que planejam o futuro de suas atividades, baseando-se na contabilidade de custos, possuem bem definidos os seus objetivos: $42 \%$ desejam construir ou ampliar a infraestrutura; $41 \%$ em maquinários e equipamentos; $33 \%$ buscam investir em novas áreas e atividades; 31\% para realização de financiamentos; $18 \%$ querem investir em aquisição de terras; e $13 \%$ planejam viabilidade para a contratação de serviços de terceiros. Os benefícios percebidos pelos entrevistados que optam pelo controle de custos e despesas da atividade foram: redução dos custos de produção e aumento dos lucros - 48\%; tomada de decisão com maior precisão - 44\%; planejamento com base na lucratividade - $40 \%$; e melhor controle - 35\%. Ressalta-se que $12 \%$ consideram que não obtiveram nenhum benefício. Foram enquadrados neste último grupo os produtores que não realizam nenhum controle de custos ou porque realmente o produtor considera que a atividade não gerou benefício.

A pesquisa revelou que apenas $34 \%$ dos produtores possuem interesse em adotar assessoria contábil rural e melhorar sua gestão amparada pelos serviços da contabilidade, enquanto que $66 \%$ não querem utilizar esse tipo de serviço. Entre as justificativas dos produtores para não aderirem à assessoria contábil, estão os altos custos que isso geraria aos usuários, destacando-se que não seria viável. Segundo os produtores, as atividades rurais nem sempre são lucrativas e, por vezes, pela interferência de intempéries, resultam em prejuízo, e a contratação da assessoria seria um custo desnecessário a ser honrado.

Outros ainda afirmaram que possuem poucas atividades e pouca movimentação financeira e que, até o presente momento, estão conseguindo gerenciar seus negócios sem necessitar do auxílio de profissionais especializados. Alguns produtores com idade mais avançada justificaram que continuam na atividade apenas para se manter, já que, depois de se aposentarem, vão mudar-se para a cidade, e quem ficará responsável por esses serviços serão os filhos. Além disso, possuem muita dificuldade no manuseio de 
Análise da Eficiência da Gestão de Custos do Processo de Produção de Arroz por pequenos e
médios produtores de Limoeiro do Norte - CE

Geanne Benevides Sá Negreiros, Rosângela Venâncio Nunes Rosângela Venâncio Nunes, Charles Washington Costa de Assis, Alexandra Alencar Siebra, Rita de Cássia Fonseca

sistemas informatizados. Outros, porém, destacaram a importância desses serviços, mas não possuem interesse neles, pois são qualificados na área ou possuem profissional especializado na família para a execução de trabalhos relacionados a esse fim; ou ainda porque já possuem sistema informatizado e profissional encarregado da gestão dos negócios.

Quanto à contratação de escritórios contábeis para a realização do imposto de renda pessoa física, contatou-se que são poucos os produtores que fazem a declaração de imposto nessa modalidade: apenas $47 \%$ do total de entrevistados. No entanto, nem todos os $53 \%$ que optaram pela resposta negativa deixam de fazer a declaração, já que alguns se enquadram na isenção, e outros cumprem a obrigação por intermédio do sindicato rural, além daqueles que não realizam a declaração do imposto por negligência.

\subsection{Análise Cruzada dos Dados}

Os dados apresentados na Tabela 1 abaixo revelam que, dos produtores entrevistados que se enquadram na faixa etária de até 20 anos, bem como daqueles que estão entre os 21 e 30 anos, todos eles fazem controle de custos, enquanto que, nos produtores classificados entre os 31 e 40 anos de idade, apenas 55,6\% fazem gestão de custos contra $44,4 \%$ que não a fazem. A faixa etária com maior relevância foi a que enquadrou os produtores de 41 a 50 anos, na qual estão inclusos 40 produtores, sendo que $100 \%$ destes afirmam gerenciar seus custos. Os produtores da faixa etária seguinte, entre 51 e 60 anos, apesar de ser o grupo que compreende o maior número de entrevistados, não apresentaram unanimidade na aderência à gestão de custos, de modo que $90,7 \%$ realizam controle de seus custos, enquanto que $9,3 \%$ não o fazem. Quanto aos produtores com mais de 61 anos, $78,6 \%$ realizam algum tipo de controle de custos em oposição a $21,4 \%$, que não fazem controle algum. 
Análise da Eficiência da Gestão de Custos do Processo de Produção de Arroz por pequenos e médios produtores de Limoeiro do Norte - CE

Geanne Benevides Sá Negreiros, Rosângela Venâncio Nunes Rosângela Venâncio Nunes, Charles Washington Costa de Assis, Alexandra Alencar Siebra, Rita de Cássia Fonseca

Tabela 1

Faixa etária x Controle custos - Tabulação cruzada

\begin{tabular}{|c|c|c|c|c|c|}
\hline & & & Controle & le custos & Total \\
\hline & & & Não & Sim & \\
\hline & Até 20 anos & Contagem & 0 & 2 & 2 \\
\hline & & \% dentro de Faixa etária & $0,00 \%$ & $100,00 \%$ & $100,00 \%$ \\
\hline & De 21 a 30 anos & Contagem & 0 & 8 & 8 \\
\hline & & \% dentro de Faixa etária & $0,00 \%$ & $100,00 \%$ & $100,00 \%$ \\
\hline & De 31 a 40 anos & Contagem & 4 & 5 & 9 \\
\hline Faixa etária & & \% dentro de Faixa etária & $44,40 \%$ & $55,60 \%$ & $100,00 \%$ \\
\hline & De 41 a 50 anos & Contagem & 0 & 40 & 40 \\
\hline & & \% dentro de Faixa etária & $0,00 \%$ & $100,00 \%$ & $100,00 \%$ \\
\hline & De 51 a 60 anos & Contagem & 4 & 39 & 43 \\
\hline & & \% dentro de Faixa etária & $9,30 \%$ & $90,70 \%$ & $100,00 \%$ \\
\hline & Acima de 61 anos & Contagem & 6 & 22 & 28 \\
\hline & & \% dentro de Faixa etária & $21,40 \%$ & $78,60 \%$ & $100,00 \%$ \\
\hline Total & & Contagem & 14 & 116 & 130 \\
\hline & & \% dentro de Faixa etária & $10,80 \%$ & $89,20 \%$ & $100,00 \%$ \\
\hline
\end{tabular}

Nota. Fonte: Elaborada pelos autores (2015).

$\mathrm{Na}$ Tabela 2, tem-se o cruzamento de informação quanto à faixa etária dos produtores rurais e o tipo de controle que utilizam para gerenciar suas atividades. Diante das informações, entre os produtores com idade até 20 anos, tais como os produtores de 21 a 30 anos de idade, 50\% utilizam o controle de custos manual e $50 \%$ utilizam mais de um método, fazendo a associação entre os dois controles, como, por exemplo, o controle manual associado ao controle por meio de tabelas no Excel.

Os produtores, inseridos na faixa de 31 e 40 anos, estão subdivididos em: controle informal - $20 \%$, controle manual - $60 \%$ e tabelas informatizadas - também $20 \%$. Dos produtores com idade entre 41 e 50 anos, 20\% administram de maneira informal, sem anotações; $67,5 \%$ efetuam anotações por meio de controle manual; $5 \%$ utilizam tabelas e planilhas informatizadas; também $5 \%$ são representados por aqueles que utilizam dois sistemas de controle simultaneamente; e apenas 2,5\% possuem um sistema informatizado próprio para efetuar o controle de seus custos. 
Por outro lado, os entrevistados enquadrados na faixa etária entre 51 e 60 anos apresentam um percentual razoável de usuários do controle informal, o que representa $30,8 \%$. No entanto, a maioria opta pelo controle manual, ou seja, $54,5 \%$, enquanto que $17,9 \%$ utilizam dois tipos de controle simultaneamente. Por fim, entre produtores com idade superior a 61 anos, 27,3\% aderem ao controle informal e 54,5\% ao manual; $4,5 \%$ aderem às tabelas informatizadas, e 13,6\% utilizam-se dos controles de maneira conjunta.

Com base nessas informações, notou-se que o controle informal é crescente acompanhando o aumento das faixas etárias - e que o controle informal é mais frequente na gestão realizada pelos produtores de idade mais avançada. No entanto, essas análises não podem ser generalizadas, pois, de acordo com a pesquisa, a maior parte dos produtores entrevistados enquadra-se nas maiores faixas etárias, representando a maioria no total da amostra. 
Análise da Eficiência da Gestão de Custos do Processo de Produção de Arroz por pequenos e médios produtores de Limoeiro do Norte - CE

Geanne Benevides Sá Negreiros, Rosângela Venâncio Nunes Rosângela Venâncio Nunes, Charles Washington Costa de Assis, Alexandra Alencar Siebra, Rita de Cássia Fonseca

Tabela 2

Faixa etária x Tipo controle - Tabulação cruzada

Tipo controle

Faixa etária

Informal Manual Tabelas Sistema Mais de um Total

\begin{tabular}{|c|c|c|c|c|c|c|c|}
\hline \multirow{2}{*}{ Até 20 anos } & Contagem & 0 & 1 & 0 & 0 & 1 & 2 \\
\hline & $\%$ dentro da Faixa & $0,00 \%$ & $50,00 \%$ & $0,00 \%$ & $0,00 \%$ & $50,00 \%$ & $100,00 \%$ \\
\hline \multirow{2}{*}{21 a 30 anos } & Contagem & 0 & 4 & 0 & 0 & 4 & 8 \\
\hline & $\%$ dentro da Faixa & $0,00 \%$ & $50,00 \%$ & $0,00 \%$ & $0,00 \%$ & $50,00 \%$ & $100,00 \%$ \\
\hline \multirow{2}{*}{31 a 40 anos } & Contagem & 1 & 3 & 1 & 0 & 0 & 5 \\
\hline & $\%$ dentro da Faixa & $20,00 \%$ & $60,00 \%$ & $20,00 \%$ & $0,00 \%$ & $0,00 \%$ & $100,00 \%$ \\
\hline \multirow{2}{*}{41 a 50 anos } & Contagem & 8 & 27 & 2 & 1 & 2 & 40 \\
\hline & $\%$ dentro da Faixa & $20,00 \%$ & $67,50 \%$ & $5,00 \%$ & $2,50 \%$ & $5,00 \%$ & $100,00 \%$ \\
\hline \multirow{2}{*}{51 a 60 anos } & Contagem & 12 & 20 & 0 & 0 & 7 & 39 \\
\hline & $\%$ dentro da Faixa & $30,80 \%$ & $51,30 \%$ & $0,00 \%$ & $0,00 \%$ & $17,90 \%$ & $100,00 \%$ \\
\hline \multirow{2}{*}{ Acima 61 anos } & Contagem & 6 & 12 & 1 & 0 & 3 & 22 \\
\hline & $\%$ dentro da Faixa & $27,30 \%$ & $54,50 \%$ & $4,50 \%$ & $0,00 \%$ & $13,60 \%$ & $100,00 \%$ \\
\hline \multirow{2}{*}{ Total } & Contagem & 27 & 67 & 4 & 1 & 17 & 116 \\
\hline & $\%$ dentro da Faixa & $23,30 \%$ & $57,80 \%$ & $3,40 \%$ & $0,90 \%$ & $14,70 \%$ & $100,00 \%$ \\
\hline
\end{tabular}

Nota. Fonte: Elaborada pelos autores (2015).

A Tabela 3, a seguir, demonstra o cruzamento de informações entre o tamanho das propriedades rurais dos entrevistados com a informação dos produtores que fazem ou não o controle de custos, evidenciando que dos produtores classificados como minifúndios, ou seja, que possuem área inferior a 18 hectares de terra, 86,2\% realizam algum tipo de controle de custos, em confronto com 13,8\% que não o fazem.

Dos produtores que detêm de 18 a 72 hectares de terra, 89,5\% fazem gestão de custos, contra $10,5 \%$ que não a fazem. Enquanto isso, os produtores classificados como médios produtores rurais, por possuírem área de 72 a 270 hectares, todos eles adotam algum tipo de gestão de seus custos. O mesmo ocorre com os grandes produtores rurais, os quais possuem área superior a 270 hectares de terra. Observa-se claramente que os produtores que possuem maiores áreas de terra fazem a gestão de 

Análise da Eficiência da Gestão de Custos do Processo de Produção de Arroz por pequenos e
médios produtores de Limoeiro do Norte - CE

Geanne Benevides Sá Negreiros, Rosângela Venâncio Nunes Rosângela Venâncio Nunes, Charles Washington Costa de Assis, Alexandra Alencar Siebra, Rita de Cássia Fonseca

custos de suas atividades, pois quanto menor o tamanho da propriedade, menor foi o percentual de produtores que afirmaram realizar a gestão de seus custos.

Tabela 3

Tamanho propriedade x Controle custos - Tabulação cruzada

\begin{tabular}{|c|c|c|c|c|c|}
\hline & & & Contrc & custos & Total \\
\hline & & & Não & Sim & IOtal \\
\hline$\frac{0}{0}$ & Ató 18 hectarec & Contagem & 8 & 50 & 58 \\
\hline ర్d & Ale lo mectares & $\%$ dentro de Tamanho propriedade & $13,80 \%$ & $86,20 \%$ & $100,00 \%$ \\
\hline 흠 & 10 ató 72 & Contagem & 6 & 51 & 57 \\
\hline 흔 & 10 die 12 & $\%$ dentro de Tamanho propriedade & $10,50 \%$ & $89,50 \%$ & $100,00 \%$ \\
\hline$\frac{\pi}{0}$ & 72 a 270 & Contagem & 0 & 14 & 14 \\
\hline 읃 & & $\%$ dentro de Tamanho propriedade & $0,00 \%$ & $100,00 \%$ & $100,00 \%$ \\
\hline స్ర్ & Sunorior a 270 & Contagem & 0 & 1 & 1 \\
\hline$\stackrel{\bar{\sigma}}{\vdash}$ & superior a $2 \pi 0$ & $\%$ dentro de Tamanho propriedade & $0,00 \%$ & $100,00 \%$ & $100,00 \%$ \\
\hline & Total & Contagem & 14 & 116 & 130 \\
\hline & Tolal & $\%$ dentro de Tamanho propriedade & $10,80 \%$ & $89,20 \%$ & $100,00 \%$ \\
\hline
\end{tabular}

Nota. Fonte: Elaborada pelos autores (2015).

A Tabela 4 evidencia os resultados entre o cruzamento de dados referentes ao faturamento da propriedade em comparação com o uso ou não de controle de custos. Os dados revelam que, entre os produtores que possuem faturamento bruto anual de 25 a 50 mil reais, $76,5 \%$ gerenciam seus custos, e $23,5 \%$ não fazem nenhum tipo de controle. Dos produtores com faturamento de 50 a 100 mil, $86,2 \%$ fazem gestão de custos contra $13,8 \%$ que adotam tais procedimentos. Daqueles que se enquadram na receita entre 250 a 500 mil reais, 100\% afirmaram gerenciar seus custos, assim como ocorre com os produtores que possuem 500 mil a 1 milhão de faturamento ou acima de um milhão.

Assim como ocorre na relação da área da propriedade com a gestão de custos, esta gestão também acompanha o faturamento: quanto maior o faturamento, maior a preocupação dos produtores em relação ao gerenciamento dos custos. 
Análise da Eficiência da Gestão de Custos do Processo de Produção de Arroz por pequenos e médios produtores de Limoeiro do Norte - CE

Geanne Benevides Sá Negreiros, Rosângela Venâncio Nunes Rosângela Venâncio Nunes, Charles Washington Costa de Assis, Alexandra Alencar Siebra, Rita de Cássia Fonseca

Tabela 4

Faturamento x Controle custos - Tabulação cruzada

\begin{tabular}{|c|c|c|c|c|c|}
\hline & & & Controle & stos & Total \\
\hline & & & Não & Sim & \\
\hline & & Contagem & 8 & 26 & 34 \\
\hline & $25-50 \mathrm{mil}$ & $\%$ dentro de Faturamento & $23,50 \%$ & $76,50 \%$ & $100,00 \%$ \\
\hline & & Contagem & 4 & 25 & 29 \\
\hline & $50-100 \mathrm{mil}$ & $\%$ dentro de Faturamento & $13,80 \%$ & $86,20 \%$ & $100,00 \%$ \\
\hline Faturamento & & Contagem & 2 & 45 & 47 \\
\hline & $100-250 \mathrm{mil}$ & $\%$ dentro de Faturamento & $4,30 \%$ & $95,70 \%$ & $100,00 \%$ \\
\hline & & Contagem & 0 & 13 & 13 \\
\hline & $250-500 \mathrm{mil}$ & $\%$ dentro de Faturamento & $0,00 \%$ & $100,00 \%$ & $100,00 \%$ \\
\hline & & Contagem & 0 & 3 & 3 \\
\hline & 500 a 1 milhão & $\%$ dentro de Faturamento & $0,00 \%$ & $100,00 \%$ & $100,00 \%$ \\
\hline & & Contagem & 0 & 4 & 4 \\
\hline & acima de 1 milhão & $\%$ dentro de Faturamento & $0,00 \%$ & $100,00 \%$ & $100,00 \%$ \\
\hline & & Contagem & 14 & 116 & 130 \\
\hline Total & & $\%$ dentro de Faturamento & $10,80 \%$ & $89,20 \%$ & $100,00 \%$ \\
\hline
\end{tabular}

Nota. Fonte: Elaborada pelos autores (2015).

$\mathrm{Na}$ Tabela 5, apresenta-se o cruzamento de informações entre controle de custos e a contratação de financiamentos. Pôde-se observar que os produtores que nunca contrataram financiamento $(77,8 \%)$ controlam os seus custos, enquanto que $22,2 \%$ não utilizam controle algum. Com relação aos que já se utilizaram de contratação de financiamentos em suas atividades, 90,1\% deles fazem a gestão de custos e 9,9\% não adotam tal procedimento.

Essas informações revelam que os produtores que financiam suas atividades ou fazem investimentos praticam melhor controle de custos. Pode-se inferir que isto se deve, principalmente, para conseguir controlar as atividades e possuir recursos suficientes para honrar seus compromissos. 
Análise da Eficiência da Gestão de Custos do Processo de Produção de Arroz por pequenos e médios produtores de Limoeiro do Norte - CE

Geanne Benevides Sá Negreiros, Rosângela Venâncio Nunes Rosângela Venâncio Nunes, Charles Washington Costa de Assis, Alexandra Alencar Siebra, Rita de Cássia Fonseca

Tabela 5

Financiamento x Controle custos - Tabulação cruzada

\begin{tabular}{lllrrr}
\hline & & \multicolumn{2}{c}{ Controle custos } & \multicolumn{2}{c}{ Total } \\
& & & Não & Sim & \\
Financiamento & Contagem & 2 & 7 & 9 \\
& \multirow{2}{*}{ Não } & \% dentro de Financiamento & $22,20 \%$ & $77,80 \%$ & $100,00 \%$ \\
& \multirow{2}{*}{ Sim } & Contagem & 12 & 109 & 121 \\
& & \% dentro de Financiamento & $9,90 \%$ & $90,10 \%$ & $100,00 \%$ \\
Total & Contagem & 14 & 116 & 130 \\
\hline
\end{tabular}

Nota. Fonte: Elaborada pelos autores (2015).

A Tabela 6 apresenta informações semelhantes, porém levam em consideração aqueles que se baseiam em informações de mercado para comercializarem seus produtos, em comparação com a gestão que adotam.

Tabela 6

Informações de mercado x Controle custos

\begin{tabular}{|c|c|c|c|c|c|}
\hline & \multicolumn{2}{|c|}{ Controle custos } & \multirow[t]{2}{*}{ Total } \\
\hline & & & Não & Sim & \\
\hline \multirow{5}{*}{$\begin{array}{l}\text { Baseia-se em } \\
\text { informações } \\
\text { de mercado }\end{array}$} & \multirow{3}{*}{ Não } & Contagem & 8 & 47 & 55 \\
\hline & & $\%$ dentro de Base informacões mercado & $14,50 \%$ & $85,50 \%$ & $100,00 \%$ \\
\hline & & Contagem & 6 & 69 & 75 \\
\hline & \multirow[t]{3}{*}{ Sim } & $\%$ dentro de Base informações mercado & $8,00 \%$ & $92,00 \%$ & $100,00 \%$ \\
\hline & & Contagem & 14 & 116 & 130 \\
\hline Total & & $\%$ dentro de Base informações mercado & $10,80 \%$ & $89,20 \%$ & $100,00 \%$ \\
\hline
\end{tabular}

Nota. Fonte: Elaborada pelos autores (2015).

A Tabela 6 evidencia que, dos produtores que não se baseiam em informações de mercado, como preço das commodities na bolsa de valores, cotação do dólar e outros, $85,5 \%$ controlam seus custos e 14,5\% não controlam. Por outro lado, esses números melhoram no caso dos produtores que levam em consideração as informações de mercado para comercializarem seus produtos. Dos que consideram essas informações, 92\% controlam seus custos e apenas $8 \%$ não fazem controle algum. De modo geral, notou-se que quanto maior o produtor, maior o faturamento, sendo que 
Análise da Eficiência da Gestão de Custos do Processo de Produção de Arroz por pequenos e médios produtores de Limoeiro do Norte - CE

Geanne Benevides Sá Negreiros, Rosângela Venâncio Nunes Rosângela Venâncio Nunes, Charles Washington Costa de Assis, Alexandra Alencar Siebra, Rita de Cássia Fonseca

aqueles que se utilizam de financiamentos e utilizam informações de mercado para comercializarem seus produtos realizam um melhor controle de seus custos.

\section{CONSIDERAÇÕES FINAIS}

O objetivo desta pesquisa foi verificar em que medida os produtores rurais de Marechal Cândido Rondon - PR utilizam as informações contábeis no gerenciamento de suas atividades.

Os resultados indicam que a maioria ( $89 \%$ dos produtores) utilizam algum tipo de controle de custos na sua propriedade, mesmo que seja informal, sem nenhum tipo de anotações. O controle manual com $57 \%$ é o mais utilizado. Poucos produtores utilizam controles mais sofisticados, como planilhas de Excel, sistema informatizado ou assessoria contábil por meio de escritório de contabilidade. No cruzamento de dados, constatou-se que os controles mais sofisticados são utilizados pelos produtores mais jovens, enquanto que os produtores mais velhos utilizam os controles informais.

Conclui-se que o controle realizado pelos produtores tem como objetivo principal controlar os custos de produção e planejar o futuro das suas atividades. Assim, os controles proporcionam redução dos custos, aumento dos lucros e auxiliam na tomada de decisão.

O tamanho da propriedade e o faturamento obtido influenciam na gestão de custos, uma vez que, de acordo com o cruzamento de dados efetuado, verificou-se que, quanto maior for a propriedade e o faturamento, melhor será o controle de custos das atividades desenvolvidas na propriedade.

\section{REFERÊNCIAS}

Andrade, M. M. (2003). Introdução à metodologia do trabalho científico: elaboração de trabalhos de graduação (6a ed.). São Paulo: Atlas.

Araújo, M. J. (2013). Fundamentos do agronegócio (4a ed.). São Paulo: Atlas. 

Análise da Eficiência da Gestão de Custos do Processo de Produção de Arroz por pequenos e
médios produtores de Limoeiro do Norte - CE

Geanne Benevides Sá Negreiros, Rosângela Venâncio Nunes Rosângela Venâncio Nunes, Charles Washington Costa de Assis, Alexandra Alencar Siebra, Rita de Cássia Fonseca

Barbosa, C. A. (2008). Manual de Administração e Escrituração Rural. Viçosa, Minas Gerais: Agrojuris.

Batalha, M. O., Buainain, A. M., \& Souza Filho, H. M. (2005). Tecnologia de gestão e agricultura familiar. In: Souza Filho, H. M., \& Batalha, M. O. (orgs.). Gestão integrada a agricultura familiar. São Carlos: Edufscar.

Breitenbach, R., Brandão, J. B., \&Vitali, D. J. (2016). Gestão de custos em unidades de produção familiares especializadas no cultivo de soja no Norte do Rio Grande do Sul, Brasil. Revista Espacios, 37(23),22.

Buainain, A. M., Alves, E., Silveira, J. M., \& Navarro, Z. (2013). Sete teses sobre o mundo rural brasileiro. Revista de Política Agrícola, 22(2), 105-121.

Callado, A. A. C., \& Callado, A. L. C. (2011). Gestão de custos no agronegócio. In: Callado, A. A. C. (org.). Agronegócio (3a ed.). São Paulo: Atlas.

Callado, A. A. C., \& Moraes Filho, R. A. (2011). Gestão empresarial no agronegócio. In: Callado, A. A. C. (org.). Agronegócio (3a ed.). São Paulo: Atlas.

Crepaldi, S. A. (2009). Contabilidade Rural: uma abordagem decisorial (5a ed.). São Paulo: Atlas.

Debertolis, A. J., Alexius M. L., \& Dossa, D. (2005). Trabalhador na administração de propriedades em regime de economia familiar (2a ed.). Curitiba: SENAR- PR.

Godinho, R. F., Soares, V. E., Bertipaglia, L. M. A., \& Dian, P. H. M. (2013). Gestão empresarial em sistemas de produção de leite na microrregião de São João Batista do Glória/MG. Revista Ciência Et Praxis, 6(12), 39-50.

Hofer, E., Pacheco, V., Souza, A., \& Protil, R. M. (2011). A relevância do controle contábil para o desenvolvimento do agronegócio em pequenas e médias propriedades rurais. Revista Contabilidade e Controladoria, 3(1), 27-42.

Instituto Brasileiro de Geografia e Estatística [IBGE]. (2006). Síntese de informações de Marechal Cândido Rondon - $P R$. Recuperado de: http://biblioteca.ibge.gov.br/visualizacao/periodicos/51/agro_2006.pdf

Instituto Paranaense de Desenvolvimento Econômico e Social [IPARDES]. Perfil avançado dos municípios: Marechal Cândido Rondon - PR.Recuperado de: http://www.ipardes.gov.br/cadernos/MontaCadPdf1.php?Municipio=85960\&btOk=ok 
Análise da Eficiência da Gestão de Custos do Processo de Produção de Arroz por pequenos e médios produtores de Limoeiro do Norte - CE

Geanne Benevides Sá Negreiros, Rosângela Venâncio Nunes Rosângela Venâncio Nunes, Charles Washington Costa de Assis, Alexandra Alencar Siebra, Rita de Cássia Fonseca

Lourenzani, W. L. (2006). Capacitação gerencial de agricultores familiares: uma proposta metodológica de extensão rural. Organizações Rurais \& Agroindustriais, 8(3), 313-322.

Marion, J. C., \& Segatti, S. (2005). Gerenciando custos agropecuários. Custos e @gronegócioonline,1(1), 2-8.

Mundo Neto, M., \& Souza Filho, H. M. (2005). Problemas do crédito rural sob a ótica da Nova Economia Institucional. Revista de Ciências Gerenciais, 9(11), 92-99.

Raupp, F. M., \& Beuren, I. M. (2012). Metodologia da pesquisa aplicável às ciências sociais. In: Beuren, I. M. (org). Como elaborar trabalhos monográficos em contabilidade: teoria e prática (3a ed.). São Paulo: Atlas.

Simprini, E. S., \& Lopes, F. F. (2012). Análise Interna. In: Lopes, F. F. (org). Agroperformance: um método de planejamento e gestão estratégica para empreendimento agro visando alta performance. São Paulo, Atlas.

Souza Filho, H. M., \& Batalha, M. O. (2005). Gestão Integrada da Agricultura Familiar. São Carlos: Edufscar

Data de Submissão: 27/12/2016

Data de Aceite: 08/08/2017 